\title{
Ocorrência de Glycaspis brimblecombei sobre Eucalyptus em Chapadão do Sul, Mato Grosso do Sul
}

\author{
Ricardo de Lima Vieira ${ }^{1}$, Luis Gustavo Amorim Pessoa ${ }^{1}$, Elisângela de Souza Loureiro', \\ Nerison Luís Poersh ${ }^{1}$ \\ ${ }^{1}$ Universidade Federal de Mato Grosso do Sul, Campus de Chapadão do Sul, Chapadão do Sul, Mato Grosso do Sul, Brasil. E-mail: \\ rflorestal@outlook.com, luis.pessoa@ufms.br, elisangela.loureiro@ufms.br, nerison.poersh@ufms.br.
}

Recebido: 06/03/2017; Aceito: 06/12/2017

\begin{abstract}
RESUMO
Glycaspis brimblecombei (Moore, 1964) (Hemiptera: Psyllidae) é um inseto sugador de origem australiana que ataca várias espécies do gênero Eucalyptus, causando danos significativos na produção florestal. No Brasil, sua presença foi descrita pela primeira vez no estado de São Paulo em 2003 e posteriormente sua ocorrência foi registrada nos estados como Paraná, Goiás, Minas Gerais, Santa Catarina e Rio Grande do Sul. A ocorrência deste inseto na região nordeste de Mato Grosso do Sul foi constatada no Município de Chapadão do Sul em povoamento de Eucalyptus camaldulensis, em setembro de 2014. Causa redução da área fotossintética devido ao elevado número de conchas, seguidas da presença de fumagina em volta destas e o amarelecimento de folhas. A ocorrência desse inseto nessa região confirma o potencial dispersivo e adaptativo dessa espécie.
\end{abstract}

Palavras-chave: psilídeo-de-concha; proteção florestal; entomologia florestal

\section{Occurrence of Glycaspis brimblecombei on Eucalyptus, in Chapadão do Sul, Mato Grosso do Sul}

\begin{abstract}
Glycaspis brimblecombei (Moore, 1964) (Hemiptera: Psyllidae) is a phytogagous insect from Australia that attacks several plant species of the genus Eucalyptus and causes considerable damage to forest production. In Brazil, its presence was first described in the state of São Paulo in 2003 and was later recorded in the states of Paraná, Goiás, Minas Gerais, Santa Catarina and Rio Grande do Sul. The occurrence of this insect in northeast Mato Grosso do Sul was recorded in the municipality of Chapadão do Sul in an area planted with Eucalyptus camaldulensis, in september 2014. This insect population reduced the photosynthetic area due to the formation of a large number of galls, followed by the presence of sooty mold around these shelters and yellowing of leaves. The occurrence of this insect species in this region confirms its dispersive and adaptive potential.
\end{abstract}

Key words: gall psyllid; forest protection; forest entomology 
O cultivo de eucalipto no Estado de Mato Grosso do Sul compreende uma área estimada de 921.000 mil hectares, destacando o estado como a terceira maior área plantada no Brasil em 2015, distribuída principalmente nos segmentos de celulose e papel, siderurgia a carvão vegetal e madeira serrada. Tal produção deve-se ao incentivo da indústria de base florestal contribuindo para exploração da cultura do eucalipto, que atualmente lidera o ranking mundial de produção florestal de eucalipto com cerca de $36 \mathrm{~m}^{3} \mathrm{ha}^{-1}$ ano $^{-1}$ (IBGE, 2016). Os principais cultivos florestais no estado de Mato Grosso do Sul compreendem as culturas de eucalipto e pinus, sendo $95,0 \%$ do eucalipto cultivado destinado à produção de carvão vegetal, celulose e papel, localizados principalmente nos municípios de Ribas do Rio Pardo, Três lagoas e Brasilândia (IBGE, 2016).

O psilídeo-de-concha, Glycaspis brimblecombei (Moore, 1964) (Hemiptera: Psyllidae) é um inseto sugador exótico, nativo da Austrália, semelhante a uma pequena cigarrinha que ataca preferencialmente o gênero Eucalyptus (Myrtaceae) (Ferreira et al., 2009). Sua infestação pode ser reconhecida devido à presença de pequenos cones de cera branca em forma de concha que serve de proteção às ninfas, construída a partir de excreções açucaradas (honeydew), eliminadas após a sucção de seiva, onde as ninfas permanecem até a fase adulta (WINCKLER-FIRMINO, 2009).

Mediante a sucção de seiva há a produção de mela com o subsequente aparecimento de fumagina. Podem ocorrer a deformação de folhas, seu amarelecimento, queda e seca dos ponteiros. Pode ocorrer também a redução na fotossíntese em função da quantidade da presença de "conchas".

A primeira ocorrência deste inseto no Brasil foi em 2003, no Estado de São Paulo. G. brimblecombei teve sua ocorrência registrada nos estados do Paraná, Goiás, Minas Gerais (SANTANA et al., 2003), Santa Catarina (LUTINSKI et al., 2006) e Rio Grande do Sul (OLIVEIRA et al., 2006). A forma pela qual esse inseto foi introduzido no Brasil ainda é incerta; sua rápida capacidade de dispersão no ecossistema florestal, favorecido pela facilidade adaptativa às condições climáticas do Brasil juntamente à grande extensão de povoamentos com eucalipto contribuíram intensamente (LUTINSKI et al., 2006).

Diante do exposto, este trabalho objetivou registrar a ocorrência do G. brimblecombei na região nordeste do Estado de Mato Grosso do Sul. Nesta região foi encontrado $G$. brimblecombei em agosto de 2014, em plantas de E. camaldulensis, com nove meses de idade, conduzidas em povoamento no Campus Experimental da Universidade Federal de Mato Grosso do Sul, Campus de Chapadão do Sul (CPCS) (1847’39''S, $\left.52^{\circ} 37^{\prime} 22^{\prime \prime} \mathrm{W}\right)$. A área experimental apresenta solo do tipo Latossolo Vermelho distrófico, clima da região é do tipo tropical úmido (Aw), com estação chuvosa no verão e seca no inverno, segundo Koppen. A temperatura média anual varia de $13^{\circ}$ a $28^{\circ} \mathrm{C}$ e a precipitação média anual é de $1850 \mathrm{~mm}$.

Tais plantas, em decorrência do ataque da praga, apresentaram redução da área fotossintética devido ao elevado número de conchas, seguidas da presença de fumagina em volta destas e o amarelecimento de folhas (Figura 1). Estas observações foram feitas no mês de setembro de 2014.

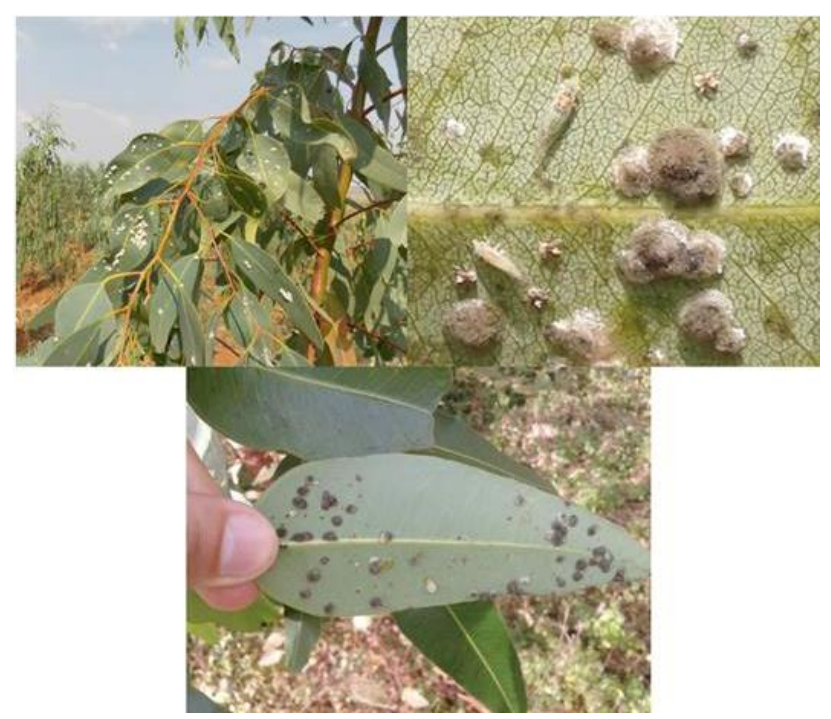

Figura 1. Eucalyptus camaldulensis infestadas com $G$. brimblecombei, em Chapadão do Sul- MS.

Para identificação do inseto, folhas atacadas foram coletadas e acondicionadas em sacos plásticos transparentes e transportadas para o Laboratório de Entomologia. Após análise em microscópio estereoscópico, observaram-se ovos, ninfas e adultos, confirmando-se a espécie através do trabalho publicado por Wilcken et al. (2003). O material coletado encontrase depositado no Laboratório de Entomologia do CPCS.

O único relato de $G$. brimblecombei em Mato Grosso do Sul ocorreu em 2003, há 14 anos, no município de Bataguassu. Desde então, a área de eucalipto tem se expandido no Estado e a geração de informações oficiais a respeito dessa importante praga não tem acompanhado o mesmo ritmo, deixando uma lacuna em relação a estudos sobre os efeitos desta praga sobre novos clones. São escassas as informações a respeito de sua bioecologia nas diferentes regiões de cultivo do eucalipto, as quais poderiam auxiliar no delineamento de estratégias de manejo mais adequadas.

O Nordeste de Mato Grosso do Sul, apesar de ainda não se caracterizar como uma grande região produtora de eucalipto, apresenta potencial para o desenvolvimento dessa cultura. De acordo com o IBGE (2016), os municípios de Chapadão do Sul, Cassilândia, 
Costa Rica e Paraíso das Águas, geograficamente próximos e localizados na referida região, apresentam 16.600 ha cultivados com eucaliptos. A ocorrência de G. brimblecombei na região é de grande relevância para confirmar o potencial adaptativo e dispersivo desta praga no Estado e no Brasil.

\section{Referências Bibliográficas}

FERREIRA, A. R.; BLAZIZA, B. A. A.; ANZOLIN, G. M.; WINCKLER-FIRMINO, C. D. Flutuação populacional do psilídeo-de-concha Glycaspis brimblecombei Moore (Hemiptera: Psyllidae) em Eucalyptus spp. no município de Garça, SP. Revista Científica Eletrônica de Engenharia Florestal, Garça-SP, v. VIII, n. 14, p. 29-46 2009.

LUTINSKI, J. A.; LUTINSKI, J. C.; GARCIA, F. R. M. Primeiro registro de Glycaspis brimblecombei Moore 1964, (Hemiptera: Psyllidae) em Eucalipto no Estado de Santa Catarina, Brasil. Ciência Rural, Santa Maria-RS, v.36, n. 2, p. 653-655, 2006.

OLIVEIRA, L. O.; COSTA, E. C.; GRELLMAN, M.; CANTARELLI, E. B.; PERRANDO, E. R. Ocorrência de Glycaspis brimblecombei Moore 1964, (Hemiptera: Psyllidae) em Eucalyptus spp. no Rio Grande do Sul, Brasil. Ciência Florestal, Santa Maria-RS, v. 16, n. 3. p. 353-355, 2006. Disponível em:<www.bioline.org.br/pdf?cf06031〉. Acesso em: 16 fev. 2017.
IBGE. INSTITUTO BRASILEIRO DE GEOGRAFIA E ESTATÍSTICA. Produção da Extração vegetal e da Silvicultura. Rio de Janeiro-RJ, v. 31, p. 1-54, 2016. Disponível

em:<https://biblioteca.ibge.gov.br/visualizacao/periodicos/74/ pevs_2016_v31.pdf. Acesso em: 09 de nov. de 2017.

SANTANA, D. L. Q.; MENEZES JUNIOR, A.; SILVA, H. D.; BELlote, A. F. G.; FAVARO, R. M. O Psilídeo-deconcha (Glycaspis brimblecombei) em Eucalipto. ColomboPR: Embrapa Florestas, 2003. 3 p. (Comunicado Técnico, 105). Disponível em:<www.ainfo.cnptia.embrapa.br/digital/bitstream/CNPF2009-09/35389/1/com_tec105.pdf>. Acesso em: 25 de fev. de 2017.

WILCKEN, C. F.; COUTRO, E. B.; ORLATO, C.; FERREIRA FILHO, P. J.; FIRMINO, D. C. Ocorrência do Psilídeo-de-concha (Glycaspis brimblecombei) (Hemiptera: Psylladae) em florestas de eucalipto no Brasil. PiracicabaSP: Instituto de Pesquisas e Estudos Florestais, 2003. 11 p. (Circular Técnica, n. 201). Disponível em:〈www.ipef.br/publicacoes/ctecnica/nr201.pdf>. Acesso em: 23 fev. 2017.

WINCKLER-FIRMINO, C. D.; WILCKEN, F. C.; OLIVEIRA, C. N.; MATOS, O. A. C. Biologia do psilídeode-concha Glycaspis brimblecombei Moore (Hemiptera, Psyllidae) em Eucalyptus spp. Revista Brasileira de Entomologia, Curitiba-PR, v. 53, n. 1, p. 144-146, 2009. Disponível em:<www.scielo.br/pdf/rbent/v53n1/30.pdf $>$. Acesso em: 26 fev. 2017. 